\title{
Pusat Pemeliharaan Kesehatan, Kecantikan, Dan Kebugaran Khusus Wanita Dengan Konsep Healing ENVIRONMENT Di SURAKARTA
}

\author{
Aini Azizati, Agung Kumoro W, Hari Yuliarso \\ Program Studi Arsitektur \\ Universitas Sebelas Maret Surakarta \\ Email : ainiazizati13@gmail.com
}

\begin{abstract}
Modern women in urban areas with high mobility, tend to be easily stress and then impact on her body fitness, beauty, and even her health. Stress has become part of modern human life, and one way to cure it is with relaxation. Nowadays not only the beauty treatments but also health care are also sought by women. There is connection between beauty and health, because they're influence and rely on each other. Beauty basically will decrease and fade, if their body not health, and vice versa. Modern women who has little time, requires an efficient and practical way of treatment to relaxation her body. This issue bring the idea to design a special space to fulfill of women needs, where is consist of health, beauty, and fitness care center. The formulation of the problems in this design is to realize six principles of healing environment. This care center is designed as a place that provides a variety of women needs from health, beauty, fitness, and also as a relaxation space. So it requires a comfortable and quiet atmosphere. Healing environment was selected as the method of design concepts, so can be expected to provide quiet atmosphere, and also can accommodate visitors to help the healing process both physically and psychologically, so that visitors can get fitter. The application of healing environment concept applied trough nature texture and material so can give perseption to visitors to feel close with nature, and health colour applied in interior trough furniture or wall colour. The application of healing environment concept in exterior applied trough healing garden with variety and colours of vegetation in exterior.
\end{abstract}

Keywords: Care Center, Healing garden, Healing environment, Surakarta.

\section{PENDAHULUAN}

Gaya hidup yang dinamis serta beragam kegiatan rutinitas sehari-hari terutama di daerah perkotaan, lambat laun akan membawa masyarakatnya pada suatu titik jenuh. Keinginan untuk tampil fit and fresh setiap saat menjadi impian semua orang, khususnya wanita aktif agar selalu terlihat cantik dan menarik.

Untuk itu sektor kegiatan perdagangan dan usaha komersial yang berkaitan dengan pelayanan kecantikan, dan kebugaran saat ini semakin berkembang. Pertumbuhan usaha kecantikan ini sejalan dengan pertumbuhan penduduk dan perekonomian yang pesat. Berkembangnya dunia kecantikan dan kebugaran terbukti dengan banyak bermunculan fasilitas kebugaran di Indonesia.

Namun seiring berkembangnya waktu, tidak hanya perawatan kecantikan saja namun juga perawatan kesehatan menjadi incaran wanita. Adanya suatu keterkaitan antara kecantikan dan kesehatan, sebab apalah gunanya kecantikan seseorang bila badannya tidak sehat. Kecantikan pada dasarnya akan menurun dan pudar, sebaliknya seseorang yang mempunyai kesehatan yang prima akan memancarkan sinar kecantikan yang alami. Dengan demikian semakin banyak kecenderungan wanita untuk mempertahankan dan sebagai upaya dilakukan berbagai cara, dari yang tradisional (alami) sampai yang modern.

Saat ini memang sudah banyak berdiri tempat-tempat pusat kecantikan, kebugaran, dan kesehatan di Kota Surakarta, namun belum ada wadah yang dapat menampung kegiatan ketiganya sekaligus dalam satu tempat sekaligus. Biasanya wadah kegiatan tersebut berdiri sendiri-sendiri. 
Berdasarkan fenomena-fenomena yang ada, khususnya di Kota Surakarta dibutuhkan suatu fasilitas baru, yaitu wadah yang mampu menaungi beberapa kegiatan atau kegiatan yang saling menunjang dan berkaitan sebagai suatu usaha untuk mengoptimalkan pelayanan dan hasil yang diterima oleh pengunjung, serta mempermudah akses dan mempersingkat waktu pencapaiannya, mengingat target sasaran dari obyek ini adalah masyarakat modern di perkotaan dengan segala kegiatannya, khususnya bagi kaum wanita, sehingga dibuatlah rancangan sebuah wadah yang berfungsi sebagai pusat yang mewadahi segala kegiatan kebutuhan wanita. "Pusat Pemeliharaan Kesehatan, Kecantikan, dan Kebugaran Khusus Wanita" dengan konsep "One Stop Service".

Pusat pemeliharaan ini harus mampu menampung 3 fungsi yang berbeda dalam satu wadah. Permasalahan tersebut dapat diselesaikan melalui pemrograman fungsional ruang untuk mendapatkan mintakat antar kegiatan. Hal tersebut dimaksudkan agar kegiatan pada masing-masing fungsi yang berbeda tersebut dapat berjalan dengan lancar, bahkan dapat saling mendukung dan menunjang satu sama lain.

Pusat pemeliharaan yang dirancang sebagai wadah yang menyediakan berbagai kebutuhan dari kebutuhan kesehatan, kecantikan, kebugaran, dan juga sebagai sarana relaksasi sehingga membutuhkan suasana nyaman dan tenang.

Dengan mempertimbangkan hal-hal tersebut, tema yang dipilih dalam proses prencanaan dan perancangan pusat pemeliharaan ini adalah penerapan prinsipprinsip healing environment. Konsep ini diharapkan dapat memberikan suasana tenang dan dapat mengakomodasi ruang gerak pengunjung, serta membantu proses penyembuhan secara fisik maupun psikologis, sehingga pengunjung dapat kembali bugar.

Perwujudan pusat pemeliharaan dengan konsep healing environment diharapkan dapat menjadi wadah bagi wanita modern di Surakarta untuk melakukan pemeliharaan kesehatan, perawatan kecantikan, dan kebugaran tubuh, dengan suasana yang nyaman dan rileks dalam satu wadah.

\section{METODE}

\subsection{Macam dan Teknik Pengumpulan Data}

Data yang dikumpulkan yakni data terkait proses perancangan, terdapat 3 macam teknik studi dalam pengumpulan data, yaitu :

\section{Studi Literatur}

Didapat melalui pengambilan informasi berupa sumber-sumber data tertulis dari beberapa buku referensi dan sumber lain seperti situs-situs internet yang memuat jenis data terkait dengan obyek perancangan. Data yang didapat dari studi literatur tersebut antara lain :

a. Teori dan artikel tentang fasilitas kesehatan wanita, fasilitas kecantikan, fasilitas kebugaran, dan fasilitas penunjang lainnya.

b. Teori dan artikel yang berhubungan dengan healing environment.

c. Teori dan artikel tentang kesehatan wanita, gaya hidup wanita, kebugaran, serta kecantikan.

d. Teori dan artikel yang berhubungan dengan sarana relaksasi.

2. Studi Observasi

Didapat melalui kegiatan survei lapangan untuk mengetahui kondisi dan potensi lokasi dan keadaan fasilitas terkait dengan obyek perancangan untuk mencari data dan sampel.

3. Studi Komparasi

Merupakan studi yang dilakukan untuk lebih mendukung obyek pembahasan, selain itu dilakukan juga studi banding dari obyek yang memiliki latar belakang atau pendekatan konsep yang sama dengan obyek perencanaan dan perancangan.

\subsection{Metode Analisis Data}

Proses analisis melibatkan pengolahan data yang dikumpulkan. Analisis perencanaan dilakukan dengan mengidentifikasi permasalahan pada data yang diperoleh melalui pengamatan, yang kemudian diimbuhi dengan literatur dan isu terkini sebagai upaya untuk menyelesaikan permasalahan.

Analisis perancangan dilakukan dengan mengolah data dan isu yang telah terkumpul, kemudian dikelompokkan berdasarkan pemrograman fungsional ruang, tampilan bangunan, dan arsitektural. 
1. Pemrograman fungsional bertujuan untuk mengidentifikasi penggunaan pusat pemeliharaan, di antaranya pelaku kegiatan, jenis kegiatan, pola kegiatan, sifat kegiatan, kebutuhan ruang, dan mintakat ruang.

2. Pemrograman tampilan bangunan diterjemahkan melaui persyaratan pemilihan tapak, persyaratan kebutuhan ruang, persyaratan besaran ruang dan program ruang, serta penggunaan metode rancang bangun yang akan diterapkan pada bangunan.

3. Analisis arsitektural merupakan tahap penggabungan dari hasil identifikasi kedua analisa sebelumnya (fungsional ruang dan tampilan bangunan). Dalam proses ini, akan dilakukan analisa masalah massa, ruang, tampilan, pengolahan tapak, utilititas, dan struktur bangunan.

\section{ANALISIS}

\subsection{Analisis Peruangan}

Peruangan yang direncanakan sesuai fungsi, kebutuhan ruang dan program ruang dari pelaku kegiatan. Peruangan terbagi ke dalam tujuh area yang dikelompokkan sesuai perwadahan kegiatan (Tabel 1).

1. Area penerima difungsikan untuk mewadahi kegiatan penerimaan seperti misalnya ruang tunggu dan lobby.

2. Area kesehatan difungsikan untuk mewadahi kegiatan pemeliharaan kesehatan yang terdiri dari beberapa klinik dokter spesialis.

3. Area kecantikan difungsikan untuk mewadahi kegiatan pemeliharaan kecantikan yang terdiri dari kegiatan perawatan kecantikan medis dan non medis berupa salon.

4. Area kebugaran difungsikan untuk mewadahi kegiatan pemeliharaan kebugaran yang terdiri dari kegiatan pelatihan kebugaran berupa sport center dan kegiatan perawatan kebugaran berupa Solus Per Aqua (SPA).

5. Area interaksi difungsikan untuk mewadahi kegiatan interaksi seperti diskusi dan pameran oleh kelompok komunitas maupun individu.
6. Area pengelola difungsikan untuk mewadahi kegiatan administratif dan pengelolaan pada pusat pemeliharaan.

7.Area servis difungsikan untuk mewadahi kegiatan penunjang pada pusat pemeliharaan.

Tabel 1.Kebutuhan Ruang

\begin{tabular}{|c|c|c|}
\hline PELAKU & KEGIATAN & PERUANGAN \\
\hline \multirow{4}{*}{$\begin{array}{l}\text { Semua } \\
\text { pelaku }\end{array}$} & Transit & \multirow[t]{4}{*}{ Area penerima } \\
\hline & $\begin{array}{l}\text { Mencari } \\
\text { informasi }\end{array}$ & \\
\hline & Menunggu & \\
\hline & Kegiatan lain & \\
\hline \multirow[t]{2}{*}{$\begin{array}{l}\text { Pengunju } \\
\text { ng dan } \\
\text { Praktisi } \\
\text { (dokter \& } \\
\text { perawat) }\end{array}$} & $\begin{array}{l}\text { Melakukan } \\
\text { kegiatan } \\
\text { pemeliharaan } \\
\text { kesehatan }\end{array}$ & \multirow[t]{2}{*}{ Area kesehatan } \\
\hline & Kegiatan lain & \\
\hline \multirow[t]{2}{*}{$\begin{array}{l}\text { Pengunju } \\
\text { ng dan } \\
\text { Praktisi }\end{array}$} & $\begin{array}{l}\text { Melakukan } \\
\text { kegiatan } \\
\text { pemeliharaan } \\
\text { kecantikan }\end{array}$ & \multirow[t]{2}{*}{ Area kecantikan } \\
\hline & Kegiatan lain & \\
\hline \multirow[t]{2}{*}{$\begin{array}{l}\text { Pengunju } \\
\text { ng dan } \\
\text { Praktisi }\end{array}$} & $\begin{array}{l}\text { Melakukan } \\
\text { kegiatan } \\
\text { pemeliaraan } \\
\text { kebugaran }\end{array}$ & \multirow[t]{2}{*}{ Area kebugaran } \\
\hline & Kegiatan lain & \\
\hline \multirow{4}{*}{$\begin{array}{l}\text { Semua } \\
\text { pelaku }\end{array}$} & Berkumpul & \multirow[t]{4}{*}{ Area interaksi } \\
\hline & Diskusi & \\
\hline & $\begin{array}{l}\text { Menonton } \\
\text { pameran }\end{array}$ & \\
\hline & Kegiatan lain & \\
\hline Pengelola & $\begin{array}{l}\text { Melakukan } \\
\text { kegiatan } \\
\text { pengelolaan }\end{array}$ & Area pengelola \\
\hline Servis & $\begin{array}{l}\text { Kegiatan } \\
\text { penunjang }\end{array}$ & Area servis \\
\hline
\end{tabular}

Pada Tabel 1 dapat terlihat kebutuhan peruangan yang dibutuhkan dalam pemenuhan wadah pada pusat pemeliharaan.

\subsection{Analisis Lokasi}

Penentuan tapak dipengaruhi oleh beberapa faktor sehingga sangat menentukan prospek bangunan tersebut.

1. Tujuan

Mendapatkan lokasi dan kawasan yang sesuai dengan kriteria perancangan. 
2. Dasar Pertimbangan:

Proses analisis melibatkan data Rencana Tata Ruang Wilayah Kota Surakarta, faktor yang sangat penting yaitu tapak merupakan lahan tidak produktif yang dapat diolah sesuai persyaratan arsitektur healing environment, tapak berada pada area yang strategis dan mudah dijangkau oleh masyarakat, serta tapak dilengkapi oleh sarana dan prasarana kota.

\subsection{Analisis Pencapaian}

Pencapaian ke dalam bangunan harus mudah diakses, mudah dilihat dan memiliki sirkulasi yang aman akan menstimulus orang untuk masuk dalam area bangunan.

1. Tujuan:

Menentukan main entrane dan service entrance.

2. Dasar Pertimbangan:

Kemudahan akses, sirkulasi tapak yang mudah diakses, arus kendaraan, potensi jalan, dan tingkat keamanan.

3. Proses Analisis

Main Entrance (ME)

Mudah dijangkau dan terlihat dengan jelas. Menghadap langsung ke arah jalan utama untuk kemudahan sirkulasi kendaraan masuk dan ke luar tapak.

Service Entrance (SE)

Tidak mengganggu keberadaan ME, dan tidak terlihat dari bagian muka tapak.

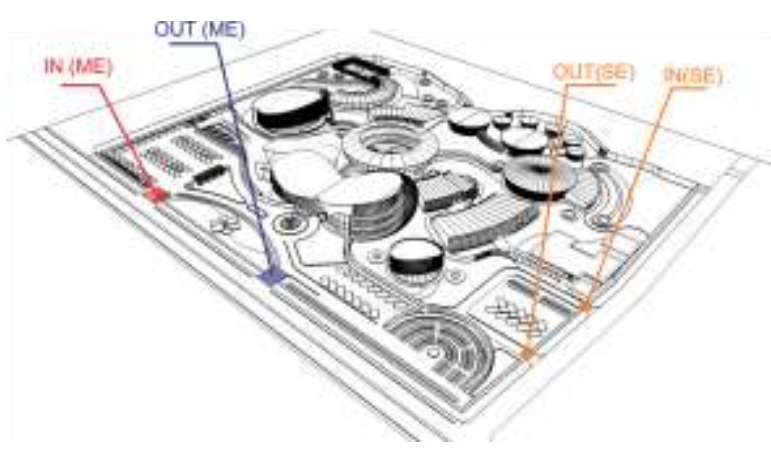

Gambar 1. Pola Pencapaian

\subsection{Analisis Pemintakatan}

Pemintakatan berfungsi untuk mengelompokkan mintakat berdasarkan sifat kegiatan dan keadaan dalam tapak guna sebagai acuan dalam penataan peruangan pada tapak.
1. Tujuan:

Menentukan mintakat berdasarkan sifat kegiatan dan keadaan pada tapak.

2. Dasar Pertimbangan:

Analisis peruangan, analisis pengolahan tapak, analisis struktur.

3. Proses Analisis:

Persyaratan ruang, berdasarkan kelompok kegiatan dan analisis pengolahan tapak.

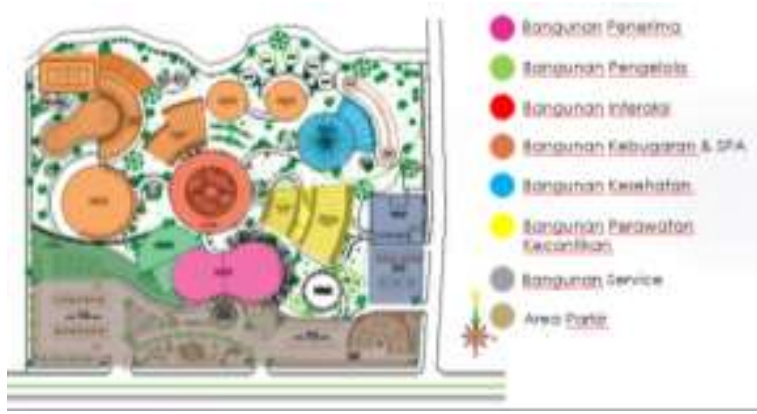

Gambar 2. Analisis Pemintakatan

\subsection{Analisis Bentuk dan Tampilan Bangunan}

\subsubsection{Analisis Bentuk Bangunan}

Citra pada tampilan bangunan diambil dari citra wanita yang luwes dan dinamis, sehingga bentuk bangunan mempunyai banyak sudut yang melengkung.

\subsubsection{Penampilan Bentuk Dasar Bangunan}

Bentuk dasar bangunan yang melengkung selain diadopsi dari citra perempuan juga merupakan salah satu respon desain terhadap bentuk tapak yang meliuk-liuk mengikuti bentuk aliran sungai yang menjadi batas utara pada utara tapak. Selain itu bentuk lengkung mempunyai sisi feminin lebih, jika dibandingkan dengan bentuk persegi yang terkesan masif.

Berikut merupakan hal lain yang menjadi pertimbangan dalam pemilihan bentuk lengkung dan lingkaran.

1. Fleksibilitas bentuk.

2. Macam sifat yang diwadahi.

3. Pengkoordinasian masing-masing kegiatan.

4. Memiliki karakter bangunan yang unik dan menarik perhatian..

5. Estetika bentuk.

Berdasarkan kelebihan bentuk lengkung maka dipilih bentuk elips dan 
lingkaran sebagai bentuk dasar perancangan.

\subsection{Analisa Elemen Tata Ruang Luar dan Tata Ruang Dalam}

1. Tujuan: menentukan penataan elemen ruang luar maupun dalam sesuai dengan prinsip healing environment.

2. Dasar Pertimbangan:

Prinsip-prinsip healing environment berupa pengolahan softscape dan hardscape pada elemen ruang luar, dan penerapan warna, material, serta pencahayaan pada elemen ruang dalam.

3. Proses Analisis

a. Tata ruang luar

Konsep healing environment diterapkan pada tapak dengan pembagian zonasi ruang $40 \%$ untuk area terbangun dan $60 \%$ yang difungsikan sebagai RTH pada tapak. Perluasan area terbuka hijau pada tapak juga difungsikan sebagai area healing garden yang merupakan salah satu komponen pembentuk elemen ruang luar pada konsep healing environment. Berikut merupakan prinsip-prinsip healing garden menurut John. S. Ormshee dalam jurnal "Landscape Architecture":

- Simplicity

Hal penting dalam mendesain healing garden, adalah kesederhanaan, agar mudah dimengerti.

- Variety (keanekaragaman)

Keanekaragaman,tekstur,

bentuk,suasana, serta warna diperlukan untuk memberikan kesan yang tidak monoton,sehingga dapat memberikan stimulan kepada pelaku

- Balance (keseimbangan)

Keseimbangan ruang merupakan hal yang penting,sehingga ruang yang tercipta stabil sebagai satu kesatuan.

- Emphasis (menimbulkan perhatian)

Dengan menggunakan petunjuk,penggolongan,tanaman untuk menciptakan sesuatu yang berbeda sehingga menimbulkan perhatian, sehingga memberikan acuan dan membantu seseorang untuk menyesuaikan diri dengan lingkungan.

- Sequences (urut)
Tatanan/ transisi yang urut dari area lansekap ke area landscape yang lain penting untuk menciptakan sirkulasi yang baik.

- Scale (skala)

Penggunaan skala yang tepat sangat penting untuk menciptakan suasana yang nyaman dan dapat menyamakan semua indera.

Prinsip-prinsip healing garden tersebut kemudian diterapkan pada pengolahan softscape berupa vegetasi dan pengolahan hardscape berupa perkerasan dan dekorasi pada taman.

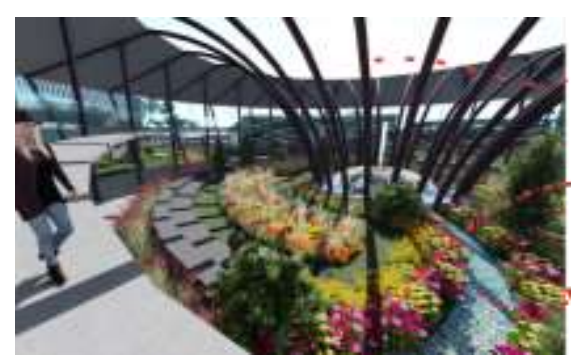

Gambar 3. Penerapan Healing Garden

b. Tata ruang dalam

Konsep healing environment diterapkan melalui penerapan prinsip-prinsip healing environment yang dikemukakan beberapa ahli melalui aplikasi pada interior ruang. Berikut merupakan prinsip-prinsip healing environment:

- Menyamakan semua indera

- Pencahayaan yang sehat

- Skema warna yang sehat

- Penghawaan yang bersih

- Material alami

- Koneksi dengan alam

Prinsip-prinsip healing environment tersebut kemudian diterapkan pada elemen pembentuk ruang berupa skala ruang, tektur dan material bahan, skema warna pada cat dinding, pencapaian ruang, serta organisasi pembentuk ruang. 


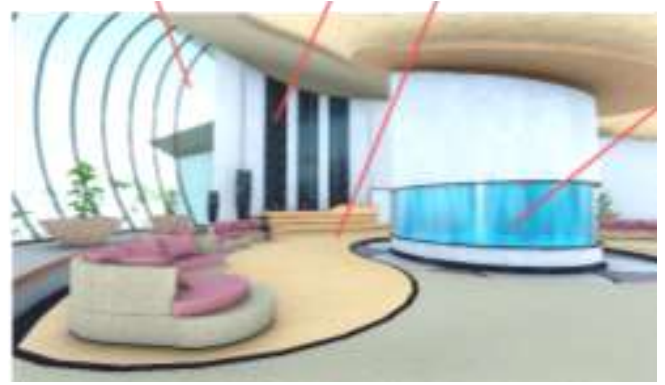

Gambar 4. Penerapan Interior Ruang

\section{Analisa Struktur}

Tujuan: mendapatkan sistem struktur yang sesuai dengan pembebanan.

Dasar Pertimbangan: beban yang harus didukung, kondisi tanah, bentuk dan dimensi vertikal bangunan, karakter bangunan, pengaruh terhadap lingkungan sekitar.

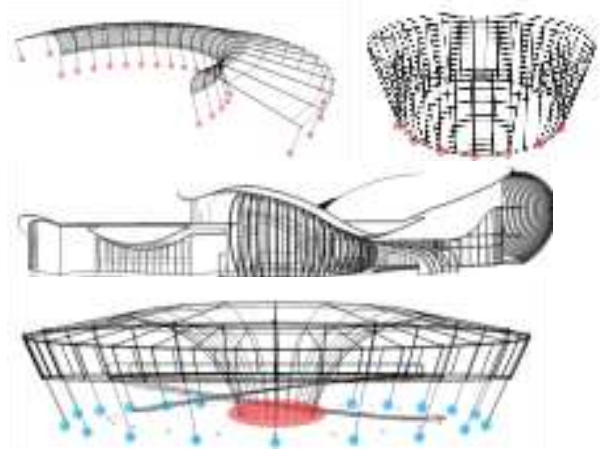

Gambar 5. Analisis Struktur

\section{Sub Structure}

Merupakan struktur pondasi bangunan yang menopang seluruh beban bangunan, sehingga pemilihan sub structure yang digunakan berdasarkan pertimbangan :

a. Ketinggian bangunan yang direncanakan

b. Kondisi tanah pada tapak

c. Jenis pondasi

d. Jenis upper dan supper structure yang digunakan

Untuk itu dibutuhkan sistem struktur yang kokoh untuk menahan beban-beban tersebut. Pondasi batu kali dan footplate merupakan penyelesaian yang cocok bagi struktur pondasi bangunan ini.

\section{Upper Structure}

Upper structure merupakan struktur badan bangunan yang berfungsi menahan beban tidak hanya beban atap tetapi juga menahan beban-beban yang bekerja pada bangunan akibat kegiatan yang terjadi di dalam bangunan tersebut.

Untuk itu dibutuhkan sistem struktur yang kokoh dan kaku untuk menahan beban-beban tersebut. Mengingat bangunan terdiri dari multi massa maka upper structure yang digunakan bervariatif menurut fungsi kegiatan yang diwadahi.

a. Struktur rangka bentang lebar merupakan penyelesaian yang cocok bagi bangunan penerima serta bangunan sport center yang membutuhkan space yang luas.

b. Struktur rigid frame merupakan penyelesaian bagi bangunan lainnya.

3. Super Structure

Bangunan pusat pemeliharaan memiliki bentuk yang hampir semua melengkung, hal ini menjadi pertimbangan pada pemilihan super structure. Berikut merupakan macam-macam penutup atap yang digunakan pada bangunan.

a. Struktur atap dag beton.

b. Struktur atap space frame yang kemudian dilapisi dengan penutup atap tegola.

c. Struktur atap payung, yang terdiri dari portal besi yang kemudian dilapisi dengan atap tegola.

\section{KESIMPULAN (KONSEP DESAIN)}

Konsep rancangan Pusat Pemeliharaan Kesehatan, Kecantikan, dan Kebugaran Khusus Wanita mengacu pada prinsip healing environment, di sisi lain bentuk bangunan yang ditonjolkan sebagai estetika serta citra bangunan yang menunjukkan karakter sisi feminin. 


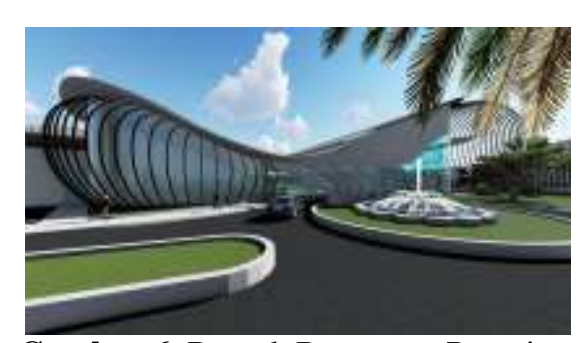

Gambar 6. Bentuk Bangunan Penerima

Dari hasil analisa serta korelasi beberapa data diatas, maka diperoleh hasil berupa rancangan Pusat Pemeliharaan Kesehatan, Kecantikan, dan Kebugaran Khusus Wanita dengan konsep Healing Environment sebagai berikut :

Lokasi : Jl. Adi Sucipto

Luas Lahan : $40.000 \mathrm{~m}^{2}$

Luas Bangunan $: 18.402 \mathrm{~m}^{2}$ Daya Tampung Kegiatan : Area komersil

Sebagai pusat pemeliharaan yang menerapan prinsip-prinsip healing environment diharapkan dapat menjadi wadah untuk membebaskan tubuh (body),pikiran (mind), dan jiwa (soul) dari segala bentuk tekanan dan ketidakseimbangan tubuh sehingga tercipta sebuah harmoni yang melahirkan energi positif diri seseorang, dan dapat bugar kembali.

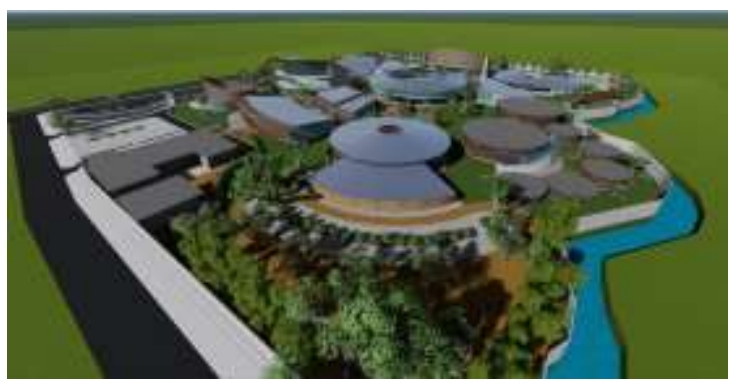

Gambar 7. Gambar Perspektif Kawasan

Berikut merupakan perwujudan konsep healing environment pada bangunan melalui elemen tata ruang luar maupun tata ruang dalam bangunan.

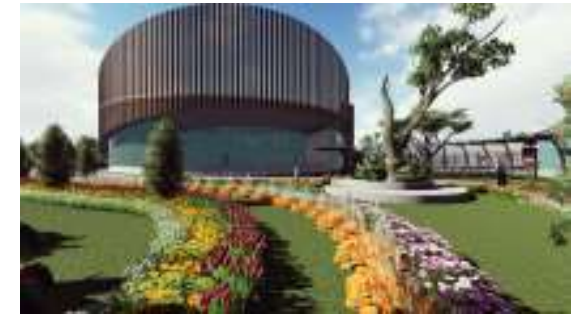

Gambar 8. Tata Lansekap pada Ruang Luar Bangunan

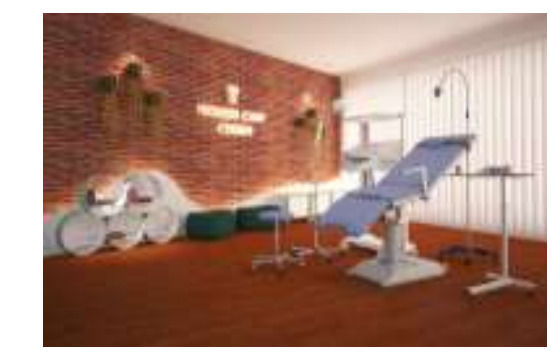

Gambar 9. Tata Interior pada Klinik Gigi

\section{REFERENSI}

Marry Ann Liebert, Inc, 2004, Journal Landscape Architecture. Tidak dicetak.

Schaller, Brian. 2012. Thesis Architectural Healing Environment. Tidak dicetak.

www.bappeda.surakarta.go.id

www.arch.ttu.edu

www.wikimapia.com 